\title{
COMPOSITE INDEXES ECONOMIC AND SOCIAL PERFORMANCE: DO THEY PROVIDE VALUABLE INFORMATION?
}

\author{
Wojciech NASIEROWSKI \\ University of New Brunswick, Fredericton, NB, E3B 5A3, Canada \\ e-mail: nasierow@unb.ca
}

\begin{abstract}
This paper examines the information content of the selected composite indexes, namely the Global Competitiveness Report Index, the Human Development Index, the Knowledge Economy Index, the Innovation Union Scoreboard, and the like. These indexes are examined from the viewpoint of country rankings. It is argued that these indexes provide highly similar information, which brings to question the usefulness of such a variety of approaches. This paper also explores the drawbacks of composite indexes, and questions whether these indexes can adequately serve as policy-setting mechanisms.
\end{abstract}

Keywords: macroeconomic analyses, economic activity evaluation, classification, economic development.

\section{$1 \quad$ Introduction ${ }^{1}$}

As stated by Adam F. (2014, p.10): "Today we are witness to an explosion of innovation scoreboards and surveys attempting to show and compare the results of innovations in the broadest of terms. We divide them into innovation scoreboards and surveys dealing specifically with innovation [such as the Union Innovation Scoreboard (IUS), the Global Innovation Index (GII) etc. I and those that deal with wider topics such as competitiveness but partly also dedicate themselves to innovation. We regard those as innovation scoreboards and reports in the broader sense [eg. the Innovation Union Competitiveness Report (IUCR), the Global Competitiveness Report (GCR). The World Competitiveness Yearbook (WCY)]."

Composite indexes are used in a variety of economic performance and policy areas. Such indexes integrate large amounts of information into easily understood formats, and can be manipulated to produce desired interpretation. Despite this, there are several methodological problems regarding the creation of com-

\footnotetext{
${ }^{1}$ Please note around 10 years ago, I had published a paper that used a similar idea. This current version is very much extended with updated data, improved methodology, several new concepts on how to handle the problem of composite indexes. Its abbreviated version was presented during Annual Spain Business Research Conference in Barcelona organized by the World Business Institute in 2016 .
}

posite indexes (Saisana \& Tarantola, 2002). Several issues arise when examining the accuracy and reliability of these indexes. Problems of missing data are imminent, along with the question of index sensitivity to the weighing of indicators and their aggregation (Freudenberg, 2003, p.5).

Composite indexes utilize a variety of indicators (data series) to measure phenomena identified by their authors. Freudenberg (2003) provides an extensive overview of composite indicators of country performance, examining groups related to economy, environment, globalization, society, and innovation/technology. The following indexes have been selected for the purpose of detailed examination in this report: The World Competitiveness Report Index (WCY, 2014), the Human Development Index (HDR, 2013), Knowledge Economy Index (KAM, 2012), the Innovation Union Scoreboard (IUS 2014; IUS 2015), the Global Innovation Index (GII, 2014), and the Global Competitiveness Report Index (GCR, 2014). Also, data series related to Purchasing Power Parity (PPP) and Productivity (PROD) have been utilized.

Composite indexes indicate which items of economic performance may contribute to the enhancement of an economy. This information may be useful in providing policy formulation suggestions for governments. "In this context there has been a movement towards the development of (internationally) comparable indicators - to compare the performance 
of individual countries or regions" (Freeman and Soete, 2007; Smith 2006; Fagerberg 2006), including the making of general composite indexes (Handbook on constructing composite indicators 2008; Archibugi et al. 2009) and "international scoreboards and country comparisons" (Adam, 2014, p.10). An inherent assumption is made that some "policies," as measured by these indicators, will produce similar results irrespective of specific and varying country context. This assumption, however, may be incorrect. An overview of literature results suggests that indexes used to measure economic phenomena demonstrate substantial overlaps and redundancy. From the viewpoint of outcome or statistical-type assessments, such variety may be deemed unnecessary. To that end, it is worth examining whether a more simplistic composite index of innovativeness can be formed, and eventually enhanced for a broader range of countries.

The primary purpose of this paper is to discuss the information content of indexes for each country, and the validity of composite indexes. To that effect, the paper is organized as follows. Section 2 introduces the key composite indexes of economic performance selected for examination. In Section 3, rankings produced by these composite indexes are compared. Also, composite indexes are examined from the perspective of information content they carry (factor analysis). Then, in Section 4, some general observations regarding the idea of composite indexes are provided. These are mainly negative comments. A conclusion follows along with recommendations for further study.

\section{An overview of composite indexes of economic - performance}

1) The WCY Index (2014) is prepared by IMD. Its objective is to analyze the facts and policies that shape a nation's ability to create and maintain an environment of value creation for its enterprises and more prosperity for its people (WCY, 2014, p.15). Based on the 312 criteria, including data from various sources and an annual Executive Opinion Survey, data are grouped into 4 categories:

- economic performance, which measures the macroeconomics of the domestic economy,
- government efficiency, which evaluates the extent to which government policies are conducive to competitiveness,

- business efficiency, which assesses the extent to which enterprises are performing in an innovative, profitable, and responsible manner,

- infrastructure, which denotes the extent to which basic, technological, scientific, and human resources meet the needs of business.

2) The HDI (2013), prepared within the United Nations Development Program, is a "composite index measuring average achievement in three basic dimensions of human development:"

- life expectancy at birth,

- mean years of schooling,

- gross national income per capita.

These represent indicators of a long and healthy life, knowledge, and decent standard of living (HDI, 2013, Technical note 1).

3) The KEI of the World Bank is prepared based on the Knowledge Assessment Methodology (KAM) (KAM, 2012), and highlights the importance of knowledge for long-term economic growth based on the averages of sub-indexes. Some 80 data series are grouped as follows:

- knowledge index,

- economic incentive regime,

- innovation system,

- education and human resources,

- information infrastructure.

This information forms the basis for identifying four sub-indexes, emphasizing the use of the existing and new knowledge, and the flourishing of entrepreneurship:

- an educated and skilled population to create, share, and use knowledge well,

- a dynamic information infrastructure to facilitate the effective communication, dissemination, and processing of information,

- an efficient innovation system of firms, research centers, universities, consultants, and other organizations to tap into a growing stock of global knowledge, to assimilate and adapt it to local needs, and to create new technology. 
4) The IUS (IUS 2015) is published by the European Commission (Sajeva et.al, 2005; IUS 2014 - earlier EIS 2005). To create the IUS Index, 25 indicators are selected arbitrarily based on relevancy and data availability. Later they are grouped into eight scales based on "expert knowledge." The following scales with indicators related to eight categories have been identified (items of these scales are listed in IUS (2015, Annex A):

- human resources,

- research systems,

- finance and support,

- firm investment,

- linkages and entrepreneurship,

- intellectual assets,

- innovation,

- economic effects.

5) The GII (2015) "covers 141 economies, accounting for $95.1 \%$ of the world's population, and $98.6 \%$ of the world's Gross Domestic Product. The GII 2015 relies on two sub-indices, the Innovation Input Sub-Index and the Innovation Output Sub-Index, each built around key pillars. The following five input pillars capture the elements of the national economy that enable innovative activities:

- institutions,

- human capital and research,

- infrastructure,

- market sophistication,

- business sophistication.

The following two output pillars capture the actual evidence of innovation outputs:

- knowledge and technology outputs,

- creative outputs.

Each pillar is divided into sub-pillars, and each subpillar is composed of individual indicators (79 in total). The sub-pillar scores are calculated as the weighted average of individual indicators; the pillar scores are calculated as the weighted average of subpillar scores. Three measures are then calculated:

- the Innovation Input Sub-Index is the simple average of the first five pillar scores,

- the Innovation Output Sub-Index is the simple average of the last two pillar scores,
- the overall GII is the simple average of the Input and Output Sub-Indices (GII, 2015).

6) The GCR 2015-2016 assesses the competitiveness landscape of 140 economies, providing insight into the drivers of their productivity and prosperity. It is build on three pillars:

Basic requirements:

- institutions,

- infrastructure,

- macroeconomic environment,

- health and primary education.

Efficiency enhancers include:

- higher education and training,

- goods market efficiency,

- labor market efficiency,

- financial market development,

- technological readiness,

- market size.

Innovation and sophistication include:

- business sophistication,

- innovation.

It also considers aspects related to technology, foreign trade and investment, domestic competition, business operations and innovation, security, governance, health, travel and tourism, environment, and risks.

Each composite index consists of sub-indexes, where all items are equally weighted. This methodology may be challenged for correctness in terms of selecting (and grouping) indicators: numbers should indicate the number and nature of the factors that describe the idea, and not the arbitrary decisions of authors of indexes. Moreover, several items are highly correlated - they carry the same information with regard to statistical significance of results (and country rankings). This methodology, in principle, is characteristic of all composite indexes presented.

\section{Information content in composite indexes}

In light of the previous discussion, this section reverts to the opening research question - what is the information content of indexes? As illustrated in the earlier section, there are several composite indexes. 
They use somewhat similar methodologies and data series to calculate a composite index. To that end, they may produce similar results - regardless of whether they intend to measure the level of innovative capability (IUS, GII), level of competitiveness (WCY), level of well-being (HDI), level of growth capability (GCI), knowledge base (KAM), or the level of competitiveness (GCI). Additionally, two easily available data series - Purchasing Power Parity (PPP), and Labor Productivity (PROD) - that may have similar information content as composite indexes, have been included.

To assess the magnitude of information content in various indexes, the Pearson correlation coefficient (Table 1) was used. If only the issue of ranking countries' performance for the purpose of general public papers was at stake, then it would be enough to use the Spearman correlation coefficients (eg., Siegel \& Castellan, 1988) of country rankings. (Table 1), Whereas Spearman correlation coefficient allows for ranking of countries, the Pearson correlation coefficient provides more precise information that also makes it possible to rank countries.

There is an overwhelming evidence; the ability of one index to provide additional information over another is questionable at best. The $\mathrm{p}$ values in all tests are all under 0.001 . Therefore, the hypothesis that different indexes produce different country rankings can be rejected. Statistical data suggest that composite indexes carry similar information. To that end, whether we examine the concept of innovativeness or wealth, we are essentially discussing closely related aspects of economic prosperity. As stated by Saltelli et al (2011), the set of challenges facing measurement of several aspects covered by composite indexes, innovation, and competitiveness in particular, is very similar, if not identical from the practical point of view.

As was indicated previously, composite indexes consist of sub-indexes. Thus, it is interesting to know how these sub-indexes are interrelated or whether they create only more redundancy. The Pearson correlation coefficients indicate that sub-indexes within each composite index are highly correlated, and almost exclusively at a statistically acceptable level 0.05 (they fall below 0.001). This indicates that not only composite indexes, but also sub-indexes are redundant for the purpose of ranking countries. Such observation indicates that the examined composite indexes have high validity, and the assessments of analyzed phenomena, made from different perspectives, produce statistically similar results.

It turns out that when factor analysis was performed for WCY, HDI, KAM, and IUS, then for each of these composite indexes, there is only one component (only for one component the eigenvalue is $>1.00$ ). Thus, the condition of item-wise scale validity is satisfied - all sub-indexes are related to one component, measure one phenomenon

For WCY, the measure of sampling adequacy (MSA) (Keiser-Meier-Ohlin $(\mathrm{KMO})) \mathrm{KMO}=0.762$. The MSA are above 0.50 . This composite index (WCY) explains $74.1 \%$ of variance of measurement of competitiveness. Factor loadings in the anti-image correlation matrix (AICM) are above 0.50. Such results indicate (and confirm) that factor analysis is an accurate approach.

Table 1. Pearson correlation coefficient for various indexes (upper triangle $-\mathrm{p}$ value, lower triangle - correlation coefficient)

\begin{tabular}{|c|c|c|c|c|c|c|c|c|}
\hline & WCY & PPP & PROD & HDI & IUS & KAM & GII & GCI \\
\hline WCY & & .000 & .000 & .000 & .000 & .000 & .000 & .000 \\
\hline PPP & .692 & & .000 & .000 & .000 & .000 & .000 & .000 \\
\hline PROD & .614 & .876 & & .000 & .000 & .000 & .000 & .000 \\
\hline HDI & .619 & .742 & .865 & & .000 & .000 & .000 & .000 \\
\hline IUS & .806 & .691 & .712 & .818 & & .000 & .000 & .000 \\
\hline KAM & .585 & .640 & .826 & .933 & .810 & & .000 & .000 \\
\hline GII & .808 & .672 & .772 & .839 & .889 & .878 & & .000 \\
\hline GCI & .944 & .688 & .642 & .636 & .814 & .620 & .834 & \\
\hline
\end{tabular}


Similarly:

- for HDI $\rightarrow \mathrm{KMO}=0.639$; MSA are above .050 . HDI explains $61.4 \%$ of variance in "wealth/wellbeing" measurement. All factor loadings in AICM are above 0.50,

- for $\mathrm{KAM} \rightarrow \mathrm{KMO}=0.514$; MSA are above 0.50 . This index explains $83.4 \%$ of variance in the area of knowledge creation. All factor loadings in AICM are above 0.50 .

There are two components (eigenvalue $>1$ ) in the case of IUS $(\mathrm{KMO}=0.807)$ : one that includes almost all items of this composite index components, and explains $58.8 \%$ of variance, and the other that deals with "open, excellent, and attractive research system" (marked as 1.2.1. - 1.2.3. in IUS 2015, appendix A), that explains $13.5 \%$ of variance. Keeping in mind the high, statistically significant correlation between the two, one can accept the notion that they are interrelated, and that there is indeed one component only. For all the examined indexes, the condition of validity is satisfied - all scales (composite indexes) are related to one item, they measure one construct.

The analysis of all discussed composite indexes (along with PPP and PROD) as if it was one "mega composite index" was undertaken. The KMO for such an index was 0.883; and MSA (in AICM) for all components are above 0.50 . Such an index forms one scale with eigenvalue $>1$, and explains $64.4 \%$ of the variance. Since there is only one component, no further rotation can be used. The examined composite indexes (as well as PPP and PROD), regardless whether they relate to wealth, innovations, competitiveness, knowledge, or knowledge creation, deal with the same phenomenon from the statistical viewpoint (here, factor analysis). They provide the same information, and consequently, may lead to the ranking of countries that is statistically significant.

\section{$4 \quad$ Further comments about constraints of composite indexes}

Composite indexes developed mainly for the purpose of comparisons of levels of innovation (competitiveness, wealth, and so on) between countries that to some extent may shed light on the suggested gov- ernmental policies oriented toward innovation enhancement. Composite indexes use a variety of indicators (data series) to measure innovations and wealth, knowledge. In such a way, they indicate which items of economic performance may contribute to the enhancement of innovations. This may provide policy formulation-related suggestions for governmental agencies, for example. Inherently, an assumption is made that some "policies," as measured by innovation indicators, will produce similar results irrespective of the specific context in various countries. This may not be a correct assumption. The results of a literature overview about innovations and the indexes used to measure it suggest a substantial overlap and redundancy of items used to assess the level of innovation of countries. Thus, it is worth verifying whether or not a more simplistic composite index of innovations can be formed, eventually enhanced to a broader range of countries, and if possible, translated in such a manner that will facilitate its use to assess innovation performance of companies.

Composite indexes normally utilize a variety of indicators (data series) to measure phenomena identified by their authors. Freudenberg (2003) provides a fairly extensive overview of composite indicators of country performance. Composite indexes consist of sub-indexes, where all items are equally weighted. This methodology may be challenged for correctness in terms of selecting (and grouping) indicators. Nevertheless, the numbers should indicate the amount and nature of the factors that describe the idea. Moreover, several items are highly correlated - they carry the same information with regard to statistical significance of results (and country rankings). This methodology, in principle, is characteristic of all composite indexes examined in this paper.

Each index captures some information related to economic improvement. Since these items are correlated, it should be asked which ones act as stimuli for the development of other ideas. Moreover, it remains unclear whether countries are innovative because they are rich, or is it vice-versa and countries with wealth are as a proverbial consequence innovative?

Composite indexes are used in a variety of economic performance and policy areas. Such indexes integrate 
large amounts of information into easily understood formats, and can be manipulated to produce desired outcomes. Despite this, there are several methodological problems regarding the creation of composite indexes (Saisana, Tarantola, 2002). Quandaries occur when examining the accuracy and reliability of these indexes. Problems of missing data are imminent, along with the question of index sensitivity to the weighing of indicators and their aggregation (Freudenberg, 2003, p.5). Composite indexes measure complex, dynamic systems, and "many of their properties emerge from interactions among the entities in them" (Katz, 2006, p.893). It has been noted that problems arise when using these indicators due to the conceptual quandary between allocative efficiency ("are we doing the right things?") versus technical efficiency ("are we doing things the right way?"). Further dilemmas stem from problematic definitions and various taxonomies used to measure the consequences of the output achieved (eg., Seng Tan, 2004). Albeit these problems, there has been a noticeable proliferation of composite indexes (eg., Archibugi, Coco, 2005, pp.179-181). With several notable problems, the need and/or usefulness of such diversity among indexes is questionable. Despite being created with different intentions, and using varying series' of data for calculations, these composite indexes may actually produce similar results when raking countries (e.g., Mirchandani, 2001). This occurs irrespective of whether they intend to measure the level of innovative capability, competitiveness, productivity, wealth, or standard of living. To that end, further studies should examine the specific information content of the selected composite indexes, so that information redundancies are minimized.

While accepting the importance of innovative activities for economic well-being of nations, it is also warranted to examine the efficiency of turning inputs of innovations into outputs that enhance social welfare. Several studies on the efficiency of organizations (systems, approaches) use the "best practice frontier" concept. Here, the distance from such a frontier represents inefficiency: in other words, the inability to produce maximum output from given inputs. Parametric approaches (e.g., regression methods) are used to estimate parameters of tech- nical efficiency. However, many elements, such as multicollinearity, model misinterpretation and measurement error, the use of multiple outputs, and omitted variables, can weaken the precision of these parameter estimates (Chapple, et al., 2005). Consequently, it may be more appropriate to depart from a cursory examination of a ratio of inputs to outputs (e.g., IUS, 2015, Sajeva, et al., 2005), and examine "best practice frontiers" from the viewpoint of contemporary economic concepts using the nonparametric DEA model in order to estimate the Farrell input - saving measure of technical efficiency. This means that the measure of technical efficiency is examined as the greatest proportion of inputs, which can be reduced and still produce the same output (Färe, Grosskopf, 1998a, p.14). Constraints of such an approach include the requirement of a specific ratio of observations (countries considered) to the number of variables (indicators) used to describe the situation.

As far as criticism related to IUS is concerned, even the leader of this approach, Hollanders expresses some concerns relative to this composite index: "To be noted: Since its inception in 2000, the EIS has been both welcomed as a relevant tool for innovation benchmarking, but has also been criticized repeatedly for not capturing all relevant dimensions of the innovation process, for using improper indicators, for not taking into account structural differences between countries, and for its methodology of summarizing countries' innovation performance using composite indicators" (Hollanders \& Cruisen, 2008, p.2). Some further critical comments relative to composite indexes, IUS in particular, can be traced in works of Schibany and Streicher (2008) and Adam (2014, pp.9-20).

\section{SUMMARY}

Composite indexes examined in this paper (along with PPP and PROD), whether they address issues of wealth, standard of living, innovations, competitiveness, knowledge creation, or knowledge, from purely statistical viewpoint, deal with the same phenomenon. They are highly correlated at a statistically significant level, use similar data series to calculate their values, use similar parametric methods, provide 
similar information, and produce similar rankings of countries. Not surprisingly, there are several valid questions: why are there such a variety of composite indexes? Is there a chance or the need to formulate one comprehensive, yet more simple composite index that may aid in enhancing efficiency and effectiveness of operational activities within the areas of concern of the existing indexes? Will not it be more beneficial to enhance stability if indexes (here: reduce changes in the use of data series), so that longitudinal studies can be performed, and hence the impact of operational policies on produced results can be undertaken?

Composite indexes of socio-economic performance are created by prestigious, influential scientific centers, and form a wide platform of evaluation of many aspects, with different "flavors" and assessment perspectives. This is the advantage of the existing situation. There is, however, a close similarity between the results they produce, that operational efforts or policy formulation aspects may be negatively affected. As well, the results these indexes provide can be manipulated (eg., through the selection of data series included in the index). Thus, it may be recommended to establish a more uniform composite index to serve needs, yet such a research goes beyond the capabilities of an independent scholar. By the same token, it should be noted that the preceding discussion does not negate the usefulness of composite indexes. Rather, the results question the need for yet other indexes, which replicates the ranking of alternate or better established measures. Each index captures some information related to economic improvement. Items of such improvement are strongly, significant; thus, some act as stimuli for the development of other ideas. Numerous studies, for years (e.g., McArtur, Sachs, 2002; Porter, 1990; Rutten, Boekema, 2005) highlight the importance of innovation to economic development and well-being. Yet, it remains unclear whether countries are innovative because they are rich, or are rich because they are innovative.

However, another line of thinking about composite indexes can as well be presented. They all produce similar results, with very similar rankings, even though different data series are used. Then it may be argued that the use of parametric approaches introduces too much simplification into discussion about innovations, health, and wealth. Since rankings remain largely unchanged (even a cursory overview indicates so), then "rich will remain rich, and poor will get more kids."

It is at times suggested that composite indexes may serve to guide policy settings. However, data series used in composite indexes change frequently (almost every year). Consequently, the possibility of identifying whether policy changes have contributed to the improvement of desired operational outcomes is limited.

There is growing evidence that the use quantitative, non-parametric methods may bring more favorable and practically useful results when assessing the economic and social performance of countries, than predominantly used parametric approaches. The coherent country groups in terms of capabilities can be identified on the basis of a system of structural equations, where composite indexes elements are classified as inputs, outputs, and moderators. Similar approach was used by Nasierowski and Arcelus (1999) when examining technological systems and National Innovation Systems. As summarized by Balzat and Hanusch, "cluster analysis techniques lead to a classification consisting of two country groups, one covering technological leaders" Nasierowski, Arcelus (1999, p.243), Nasierowski, Arcelus (2003, p.5), the other embracing emerging countries that base their technological progress mainly on the import of innovations developed abroad." [Then] through factor analysis methods, the analyzed countries are ranked according to their technological strength. In addition of these empirical tests, Nasierowski and Arcelus (2003) have developed a Data Envelopment Analysis model with the aim of studying the efficiency of National Innovation Systems. The efficiency evaluations are split into two parts, one is concerned with the measurement of efficiency in the generation of innovations - which is called "R\&D efficiency," while the second examines "R\&D productivity" (Nasierowski \& Arcelus, 2003, p.2), which is defined as "a country's efficiency in the translation of technological success into national productivity growth" (Baklazat \& Hanusch, 2004, p. 203). The similar approach can be used in order to refine composite indexes discussed in this paper, yet it calls for further extensive studies. 
Beyond the issue of composite indexes construct related to progress, it is worth to record that as far as investment if future is concerned - education and/or $R \& D$ - the US spending for R\&D is only 10 times higher than for gambling; on average, about the same amount of money is spend for R\&D (investment for future benefits) as for alcohol!!!; almost the same amount as for gambling, restaurants, entertainment drugs and movies!!! (MGF, 2010, Table 1).

Acknowledgements: Support to this study has been granted by the University of New Brunswick, Faculty of Business Administration and is gratefully appreciated. A support for statistical calculations had been granted by Tadeusz Nasierowski.

\section{$6 \quad$ References}

[1] Adam, F., 2014. Measuring National Innovation Performance - the Innovation Union Scoreboard Revisited. Slovenia, Ljubliana: Springer.

[2] Archibugi, D., Coco, A., 2005. Measuring Technological Capabilities at the Country Level: A Survey and a Menu for Choices. Research Policy, Vol 34, pp.175-194.

[3] Archibugi, D., Filippetti A., 2009. The Technological Capabilities of Nations: the State of the Art of Synthetic Indicators. Technology Forecasting and Social Change, Vol. 76 (7), pp.917931.

[4] Balzat, M., Hanusch, H., 2004. Recent trends in the research on national innovation systems. Journal of Evolutionary Economics, Vol. 14, pp.197-210.

[5] Chapple, W., Lockett, A., Siegel, D., Wright., M., 2005. Assessing the Relative Performance of U.K. University Transfer Offices: Parametric and non-parametric evidence. Research Policy, Vol. 34, Iss. 3, pp.369-384.

[6] Fagerberg, J., 2006. Introduction: a guide to literature: In: J. Fagerberg, D.C. Mowery, R.R. Nelson, eds. The Oxford Handbook of Innovation, Oxford: Oxford University Press, pp.1-26.

[7] Freeman, C., Soete, L., 2007. The Economics of Industrial Innovation, $3^{\text {rd }}$ ed., London: Routledge.

[8] Freudenberg, M., 2003. Composite Indicators of Country Performance: A critical assessment. STI Working paper 2003/16, Industry Issues, OECD JT00153477.

[9] GCR, The Global Competitiveness Report 201516. K. Schwab, ed. World Economic Forum, Geneva [online] Available at: https://www.globalinnovationindex.org/userfiles /file/reportpdf/GII-2014-v5.pdf.

[10] GII, Global Innovation Index 2014. Eds.: Soumitra, D., Bruno, L., Wunsch-Vincent, S. [online] Available at:

https://www.globalinnovationindex.org/userfiles /file/reportpdf/GII-2014-v5.pdf.

[11] GII, The Global Innovation Index 2015. Effective Innovation Policies for Development. D. Soumitra, L. Bruno, S. Wunsch-Vincent, eds. [online] Available at: http://www.wipo.int/edocs/pubdocs/en/wipo_gii 2015.pdf,

[12] Handbook on Constructing Composite Indicators, 2008. Paris: OECD.

[13] HDI, Human Development Index, 2014. Table 1. United Nations Development Programme. New York: Published for the United Nations Development Program.

[14] Hollanders, H., Cruysen, V.A, 2008. Rethinking the European Innovation Scoreboard: Recommendations for further improvements. Input paper for the workshop on Improving the European Innovation Scoreboard methodology, Maastricht,

[15] IUS, Innovation Union Scoreboard, 2013, 2014, 2015. European Commission.

[16] KAM, Knowledge Assessment Methodology Knowledge Economy Index 2012. The World Bank Institute. [online] Available at: www.worldbank.org/kam.

[17] Katz, S., 2006. Indicators for complex innovation systems. Research Policy, Vol. 35, Issue 7, pp.893-909.

[18] McArthur, J.W, Sachs, J.D, 2003. The Growth Competitiveness Index: Measuring Technological Advancement and the Stages of Development. The Global Competitiveness Report 20012002. New York: Oxford University Press for the World Economic Forum.

[19] Mirchandani, D., 1999. Economic and social indicators of global competitiveness: An analysis of country rankings, $8^{\text {th }}$ International Eastern Academy of Management Conference, (CD Rom version), Prague.

[20] Morss, E.R., 2009. The Global Economics of Gambling [online] Available at:

www.morssglob-alfinance. com/ the-globaleconomics-of-gambling.

[21] Nasierowski, W. Arcelus, F., 2003. On the efficiency of National Innovation Systems. Socio Economic Planning Sciences, 37, pp.215-234.

[22] Nasierowski, W., Arcelus, F., 1999. Interrelationships among the elements of National Innovation Systems: A statistical evaluation, European Journal of Operations Research, No 119 , pp.235-253. 